\title{
1. The sandwich generation: individual, family, organizational and societal challenges and opportunities
}

\author{
Ronald J. Burke
}

This collection addresses the challenge of balancing work and multigenerational caregiving responsibilities as an increasing number of employed women and men raise young children, support adult children, and care for aging parents while managing their own household and work responsibilities. This phenomenon is known as the sandwich generation. The term "sandwich generation" now appears in several dictionaries (e.g., Merriam-Webster, Oxford English), numerous government and media reports, and countless academic publications, becoming part of our everyday lexicon. The term first appeared in the published literature in Miller (1981).

Chisholm (1999, p.178) writes in offering a definition that "The sandwich generation refers to individuals who, by dint of circumstances, find themselves in the position of being caregivers for their young children, and/or adult children and care for one or both of aging parents." Working couples caring for children and aging parents have been called the sandwich generation or the sandwiched generation for over 25 years, with the phenomenon receiving increasing research attention over the past decade. These couples are sandwiched between the needs of children, parents and workplaces. Addressing the needs of these individuals and roles has been found to be stressful (Hammer and Neal, 2008; Duxbury and Dole, 2014). Carers UK (2013) estimated that by 2050 there would be three times more people of working age looking after 2 billion aging family members. Caregiving and careers tend to rise at roughly the same time, between 45 and 65. Thus eldercare has become an important topic. Older people also give care to their grandchildren or are custodial grandparents. In the US, 55 percent of all children under 18 lived in a household maintained by their grandparents.

The National Alliance for Caregiving and the American Association of Retired Persons (2004) reported that 21 percent of the US population provides family caregiving to someone over 18 years of age. Seventy-nine 
percent of these caregivers provided care for someone 55 years of age or older. The majority work full time or part time, and about two-thirds of employed caregivers make work-related adjustments to undertake care.

Koerin et al. (2008) examined the role of informal caregiving in the US healthcare delivery system. Over 80 percent of home-based care is provided without pay by family and friends. The majority of caregivers work full or part time (59 percent), and 62 percent made work-related adjustments to provide care. Caregiving involves addressing physical and psychological needs simultaneously. Some caregiving tasks are "hands on" (e.g., bathing, feeding, giving medications, providing support), while others are "managerial" (e.g., planning, supervision, mediating with external experts and programs). More older women and men receiving care are now living separately from their caregivers. More caregivers are also working for pay in either full-time or part-time jobs.

The traditional sandwich generation has the following characteristics: those sandwiched are in their 50s and 60s, with aging parents, children and perhaps grandchildren. This picture is slowly changing today as the population ages, with more older children remaining at home as they either cannot find jobs or cannot find jobs that pay enough for them to live on by themselves. Sandwiched parents can spend as much as $\$ 10000$ a year providing for children and aging parents, and 1350 hours a year in caregiving. A survey by the Pew Research Center in the US (2013) of 2500 adults reported that about half of the respondents aged 40 to 59 gave money in the preceding year to at least one child 18 years of age or older. More adult children have returned home while looking for work. There has also been a rise in the number of married couples living in a parent's home.

Although there is still some uncertainty about the percentage of families that fit the sandwich generation definition, estimates range from 10 percent to 20 percent worldwide depending on the variables used to classify individuals and families. Statistics Canada (2010) reported that the sandwich generation included up to 30 percent of Canadians aged 45 to 64 who are simultaneously responsible for their still dependent children under 25 and their aging parents. About one-third of US citizens are now engaged in some type of eldercare, averaging about 20 hours a week for a period of between 5 and 18 years. Women do most of the caregiving, but more men are now involved. Male caregivers are less likely than female caregivers to ask for help, feeling that they must be strong to continue. Male caregivers are also less likely to talk about the stresses and strains they experience. Most of these caregivers also have jobs. The size of the sandwich generation is expected to increase as a result of demographic, social and economic trends, including: aging populations; lengthening lifespans; delayed childbearing; smaller family sizes; more women in the 
workforce; weak economic growth; increasing healthcare costs; decreased public spending on health and social services; and the desire of the elderly to age in place. Relative to other work-family integration issues, the sandwich generation is under-studied and unique in the challenges it presents to researchers trying to make sense of this complex topic. Following is a brief overview of the issues relevant to the sandwich generation.

A wide range of disciplines are involved in the study of the sandwich generation (e.g., management, economics, gerontology, psychology, sociology, social work, social policy). Most research has been undertaken in North America, but is slowly increasing in other developed countries. National cultures and context affect the relationship of eldercare and work.

Factors that have contributed to the emergence and size of the sandwich generation include the following:

- more children living at home as they pursue higher education, look for jobs or work in low paying jobs;

- an aging population;

- the need for healthcare growing as a result;

- an increasing shift to informal care;

- less informal care available as family sizes decrease and family members move to different cities or countries;

- increases in overload on the part of caregivers;

- women and men increasingly bringing work home since they can't spend as much time at the office;

- increases in overload and stress among middle-aged women and men in sandwich generation circumstances.

A Canadian survey reported that two-thirds of parents were now supporting their adult children living at home by spending their savings (Freeman, 2015). Parents spent as much as $\$ 500$ a month to support "Generation boomerang," reducing their retirement nest-eggs. This money included providing free room and board, paying for groceries, paying for cell-phone bills, car payments or car-related expenses, paying rent for children living elsewhere, and children's debt repayments.

Caring for one's parents is generally stressful. Caregivers must balance a full-time job, their own families, and the needs of one or more parents. It is also increasingly likely that a parent will have one or more health problems. Some caregivers themselves can suffer health problems as a result of not having time or energy to take care of themselves. And the stress, strain and well-being of one spouse can cross over and affect the other spouse. But interestingly not all caregivers are in distress. One option is to have 
a person assist the caregiver. And most seniors or aging parents want to remain in their own homes as long as possible. Another option is to have the aging parent(s) needing help move into a seniors (nursing) residence. These issues will be addressed in this collection as well.

\section{WHAT WE KNOW ABOUT THE SANDWICH GENERATION AND CAREGIVING - A PARTIAL REVIEW OF THE LITERATURE}

The following sections offer a brief summary of research and writing on correlates and consequences of sandwich generation membership as it affects individuals, families and workplaces. Other reviews have been provided by Neal and Hammer (2007), DeRigne and Ferrante (2012), Calvano (2013) and Neal et al. (2013).

\section{THE SANDWICH GENERATION IS A GLOBAL PHENOMENON}

The sandwich generation is a global phenomenon (OECD, 2011). Across ten EU countries, 16 percent of adults are involved in informal unpaid caregiving. In China this figure is 36 percent. Caro (2007) edited a special issue on aging policy, with contributions from five countries (Canada, Denmark, Singapore, Sweden, the United States). Family values in these countries created considerable time, resources and effort caring for the elderly, but there was a need for greater publicly funded programs to support caregivers and caregiving in each country. Remennick (2001), in a sample of 20 middle-aged Jewish women who immigrated to Israel from Russia with their extended families, documented increasing levels of exhaustion and burnout among them resulting from caregiving and isolation.

\section{As a Global Phenomenon It Has International and Cross-cultural Caring Issues}

A colleague of mine from India has lived in Canada for several years. Her aged mother back in India needs care, which my colleague cannot undertake from Canada. My colleague has a sister still in India who lives quite a distance from their mother as well. Dhar (2011) writes about ways that globalization and the aging population are influencing transnational caregiving. More people are moving to other countries seeking jobs and 
careers, leaving their aging parents needing healthcare back home. This creates a caregiving drain in their home countries. As noted elsewhere in this chapter, some caregiving from a distance can take place using technology.

\section{As a Global Phenomenon It Requires Integrating Cultures}

Jones et al. (2002) interviewed 22 Chinese American and 19 Filipino American immigrants to the United States who were providing caregiving to parents. Caregivers' ages ranged from 38 to 68 , with most working outside the home (92 percent). Although these caregivers were moderately acculturated to the US, they were still transitioning between cultures. Respondents reported bringing their filial values of caring for their parents to the US, being in transition to their American culture, connecting with family resources and their own inner strength, and, though it was challenging, managing to integrate caregiving into their lives.

\section{As a Global Phenomenon It Highlights Country Differences}

Pines et al. (2011), using samples of dual-career couples in the sandwich generation from both Israel and the US, examined levels of job and couple burnout. They found that job burnout was higher than couple burnout, wives were more burned out than husbands, and Americans were more burned out than Israelis. Stressors generally had negative consequences, while rewards generally had positive consequences. Thus job-related stressors and rewards and parent care stressors predicted job burnout, marital stressors and rewards predicted couple burnout, and there was some evidence of cross-over of job and couple burnout and spillover of job burnout to couple burnout.

Katz (2009), based on data from five countries (Norway, England, Germany, Spain, Israel), studied relationships between dimensions of intergenerational relationships (solidarity, conflict, ambivalence) and subjective well-being (life satisfaction, positive and negative affect) of older people 75 years and above. She reports the following results. First, intergenerational family relations predicted all components of well-being. Second, personal resources, particularly physical functioning and financial adequacy, predicted all well-being measures. Third, country predicted all well-being measures, with Norway, Germany and England ranking higher than Spain and Israel on the well-being measures. 


\section{COUNTRY POLICIES AND PROGRAMS - CONSIDERABLE VARIABILITY}

Kotsadam (2011), using longitudinal panel data from 15 European Union countries, found that informal eldercare generally impacted levels of women's participation in the workforce, effects being stronger in some countries than in others. Country policies and processes of formal care reduced the impact of eldercare on women's employment. Jakobsson et al. (2013) showed that engaging in caregiving was negatively associated with being employed in both Norway and Denmark but not in Sweden, which they attribute in part to different levels and types of government support for caregiving. Lechner and Neal (1999) examine how 11 countries in different stages of development (e.g., Sweden, Germany, Mexico, Uganda) are dealing with the work-eldercare issue. Dhar (2011) addresses the complications of caregiving when caregivers live in other countries.

Zhang and Goza (2006) note the difficulties that China's one-child policy created and focus on the sandwich generation as a possible solution to China's rapidly aging population. It is obviously very difficult for one child to care for two parents and four grandparents. As a result, parents need to make their own plans for their futures. Zhang and Goza see a major role for government in providing the necessary resources and assistance.

\section{Country Differences in Types of Support Provided}

Barbosa and Matos (2014), in a 16 country study, found that Portugal had a higher prevalence of co-residential care (daily or almost daily) (12 percent), and the lowest prevalence of extra-residential care or help (11 percent). They also found that the quality of life of Portuguese co-residential caregivers was lower than the quality of life of non-caregivers, but the presence of extra-residential help or care provided once a month or less was associated with the increased quality of life of caregivers.

\section{COMPLEXITIES IN THE CAREGIVING RELATIONSHIP}

Neal et al. (1997) examined the effects of gender and relationship differences in caregiving recipient (e.g., spouse, parent, parent-in-law, other relative, friend) on employed caregivers $(n=2174)$. Female and male caregivers performed similar levels on 7 of 13 caregiving tasks (e.g., home and yard maintenance, help with expenses), but females devoted more time, emotional support and tasks performed. Type of relationship added to the 
predictability of caregiving concerns (stress, time off work), with caregivers to parents and spouses, and female caregivers reporting less favorable caregiving experiences.

Ingersoll-Dayton et al. (1996), in a sample of 1585 employed caregivers of parents and parents-in-law, studied the effects of gender and relationship type (parent or parent-in-law) on caregiving activities, resources received from recipients, and costs. Both caregiver gender and caregiving recipient's gender influenced care provided to and from parents and parents-in-law. Women provided more social support and home maintenance and indicated more stress. Female care recipients received more social support, help with their children, meal preparation and cleaning than did males. Thus there were considerable interactions between caregiver gender and type of relationship. Daughters-in-law were particularly at risk, as they received fewer resources from eldercare recipients.

Robison et al. (2009), in a sample of 4041 residents of Connecticut consisting of two subsamples, older adults (61 years of age or older) and baby boomers (42-60 years of age), considered whether caregiving negatively affected six outcomes. These included depressive symptoms, health, missing work and social isolation. Caregivers rated their health better than non-caregivers and had similar levels of both depressive symptoms and social isolation. However, living with the care recipient, inadequate financial resources, and the care receiver's unmet need for community-based long-term care services were associated with the most negative outcomes. They conclude that many caregivers need training and education, respite, and psychological and mental healthcare.

Heisler et al. (2008) examined health and social outcomes in two groups of elder adults: those moving to a continuing care retirement community locally (intra-county) and those moving into the same retirement communities from outside the county ( $\mathrm{ns}=75$ and 27 , respectively). Respondents were interviewed before the move and re-interviewed a half-year later. More longdistance-moving older adults suffered greater health declines.

Juin (2015), using a 2008 French survey of 1165 co-residing caregivers and 1194 non-co-residing caregivers, studied care arrangement effects on three caregiver health measures: self-assessed health, general health, and negative mental health symptoms. Informal care intensity was assessed by hours of care provided per week. The results indicated that informal care had a negative effect on health, primarily when it was intensive (more than 20 hours a week), for co-residing caregivers providing daily assistance compared to non-co-residing caregivers. 


\section{CAREGIVING OVER TIME, CAREGIVING STAGES AND TRANSITIONS}

Seltzer and $\mathrm{Li}$ (2000) considered transitions in the caregiving relationship in a three year prospective study involving 476 wives and daughters. Three transitions were considered: entry, institutionalization and bereavement. Daughters were more likely to enter the caregiving role than were wives, but the impact of entry was greater on wives. During caregiving, wives more than daughters decreased participation in leisure activities, had lower views of the quality of family relations and had reduced marital satisfaction. Daughters were more likely than wives to place care recipients in institutions, increase their social participation and have decreased feelings of burden after institutionalization. The same number of wives and daughters were bereaved, with wives having increased social involvement and personal growth following this.

These results shed light on the complex and dynamic nature of a caregiving career, the importance of kinship relationships between the caregiver and care recipient, and the effects of the caregiving relationship over time.

Lechner and Gupta (1996) followed up 24 people involved in full-time employment and caregiving for frail parents across a four year period. There was a significant decline in the parents' level of functioning and significant changes in the respondents' financial, social and personal lives and their levels of job satisfaction. There were also changes in respondents' physical conditions and work conditions. Respondents wanted their workplaces to make it easier for them to handle caregiving and their work roles by providing benefits and services.

\section{ETHNIC DIFFERENCES}

Del Campo et al. (2013) noted differences between Hispanics and white non-Hispanics in effects of family/friend support at home on the relationship between an organization's work-family policies and flexible scheduling and perceptions of organizational and supervisor support. White non-Hispanics saw greater organizational and supervisory support when work-family programs were offered than Hispanics when low levels of family/friend support existed, and lower organizational and supervisory support when high levels of family/friend support existed. This highlights the potentially important role of ethnicity on perceptions and use of work-family and workplace flexibility initiatives.

Cravey and Mitra (2011) highlight differences based on race and ethnicity in the US on sandwich generation demographics. Differences 
between these groups in terms of beliefs, social attitudes and values existed. They cite higher levels of being sandwiched and feeling sandwiched across both Asians and Hispanics than across Caucasians and African Americans.

\section{DEALING WITH CRISES}

England and Tripp-Reimer (2003), in a sample of 92 adult children caregivers who had experienced a crisis within the previous six months, studied their concerns and goals for caregiving and their recent crisis experiences. Most were women, first born, married, working, had provided care for six months or less, mostly for mothers, about four hours a day, involving Alzheimer's, and with most of the parents living in assisted living or nursing homes. Most of the caregiving was psychological in nature, with Alzheimer's patients being confused and needing help with judgment. Caregiving affected the caregivers' overall health adversely.

Key issues related to a crisis were health events ( 86 percent), deaths (63 percent), relocation events ( 60 percent) and family events ( 26 percent). The most common family relation events were sibling strains (63 percent), disabilities (100 percent), parental stresses (60 percent), resource difficulties (50 percent) and marital stress (44 percent). Interestingly, early childhood events and the difficulties of adult children (e.g., child abuse, departing home early) influence the roles of adult children. The distress of adult caregiving children involved existential concerns (the meaning of life, aloneness) ( 83 percent), repetitive thoughts (58 percent), suicidal ideation, midlife concerns and bereavement (63 percent) and death from natural causes. Dysfunctional coping of adult children mainly involved alcohol consumption, not elder abuse.

This study identified several important issues associated with crisis, linking several areas (family relations, early childhood experiences, dysfunctional coping). Adult caregiving children became aware of personal crisis, progressing from long-term caregiving and their own health. Adult caregivers were not well prepared for caregiving. Sibling and family strains surfaced along with the vulnerabilities of adult caregiving children. Practical implications followed from their work. Health professionals can provide assistance to help families prepare for and manage the demands of family caregiving. 


\section{TYPES OF FAMILIES}

Pyke and Bengtson (1996) found that families differed in participating in eldercare. One dimension accounting for this was the experience of individualistic or collectivistic systems of values. Individualistic families minimized informal caregiving, relying on formal support, whereas collectivistic families used caregiving to build family ties.

Grundy and Henretta (2006), in a sample of UK and US women aged 55 to 69 , found that about one-third provided care to surviving parents and partly dependent children, with about one-fifth providing care to neither. They interpreted this as support for a "family solidarity" hypothesis, an intergenerational exchange in both directions.

\section{IMPACT ON FAMILY DYNAMICS}

Szinovacz (2003) collected data from 17 adolescents to examine potential changes in parent-adolescent relationships and in family dynamics when a family member with Alzheimer's or dementia moves into the household. Adolescents reported some positive changes (e.g., more empathy and respect for primary caregiver, and helping in caregiving strengthened adolescent-parent bonds) and negative changes (e.g., limitations in own and family activities). Caregiving stress also spilled over into family relationships and caregiving parents' focus of attention on the care recipient. Thus family dynamics were affected by the outcomes of caring for a demented relative at home. Family relations are also affected by age differences in values and beliefs between children under 30 and parents or grandparents.

Lashewicz and Keating (2009), in a Canadian study of how parental care and assets are divided, found that disputes occur when siblings see others as dominating parental care and assets by separating siblings from the parent, and stopping siblings from participating in decisions about care and assets.

\section{HOW AGING PARENTS HELP THEIR CHILDREN}

Ingersoll-Dayton et al. (2001) studied ways that aging parents helped their adult children, part of the sandwich generation. They collected data from 63 focus group participants and 618 survey respondents. Aging parents helped their adult children by providing financial help, giving emotional support, undertaking childcare and performing household tasks. Survey 
data indicated that caregiving husbands and wives in the sandwich generation receiving help from parents indicated a higher relationship support and improved performance in their caregiving roles, particularly the result of emotional support. The provision of other kinds of support - financial, childcare, household tasks - was less likely to have positive effects on the relationship with sandwich generation adult children (feeling guilty about financial help from one's parents, intrusion of helping parents in their lives, creating additional work for the adult caregivers).

\section{QUALITY OF LIFE OF OLDER PEOPLE}

We are witnessing global aging. Do older people just cost money in terms of pensions and healthcare? Do older people have things to contribute to society? It seems increasingly important to better understand the components of well-being in the elderly and factors associated with increasing their quality of life. Quality of life is a multifaceted concept having subjective and objective elements, micro- and macro-levels, and positive and negative components. Quality of life includes and is affected by both individual initiatives and country policies. Mudrak et al. (2015), in a Czech sample of 846 older adults having a mean age of 68 , found that levels of physical activity predicted self-efficacy, which in turn predicted quality of life through mental and physical health status. Personality and health in middle age are also strong predictors of well-being and health in older ages (Perrig-Chiello et al., 2009).

\section{HELP TO ELDERS}

The Pew Research Center (2013) reported an increase in middle-aged adults "sandwiched" between children and aging parents, more middleaged parents supporting grown children, people increasingly believing middle-aged adults should support elderly parents rather than grown children, middle-aged parents providing both financial support and emotional support, supporting parents becoming an increasing financial burden, women and families with lower incomes providing more care, and three-quarters of respondents giving some kind of support to aging parents.

Nichols and Junk (1997) studied task assistance provided to parents of sandwiched families. Data were collected from 218 respondents: most were men ( 72 percent), most were in their 40 s (50 percent) and most were married (90 percent), with yearly annual incomes of between $\$ 35000$ 
and \$49999. Respondents resided in three western US states and one mid-western state. Fifteen percent were sandwiched between the needs of children and parents. Respondents provided more to mothers than to fathers, most parents lived with the respondents, and spouses' parents typically lived farther away. The most common assistance included providing transportation and assistance with shopping and house cleaning; less common assistance included paying bills and taxes, financial assistance, meal preparation and personal hygiene. It is also possible that both informal and formal care can increase levels of mental health and psychological well-being among the less dependent elderly.

Couch et al. (1999), in a sample of 4328 households, found that individuals earning higher wages gave more money to elderly parents and allocated less time to them than did low wage households. Some families provided several sources of support.

\section{ALZHEIMER'S VERSUS PARKINSON'S}

Hooker et al. (2000) examined whether type of disease (Alzheimer's and Parkinson's) had different effects on male and female spouse caregivers. They collected data from 175 spouse caregivers for recipients with Alzheimer's $(n=88)$ and Parkinson's $(n=87)$ using interviews and questionnaires. Wives in the Alzheimer's group indicated significantly worse mental health outcomes (stress, depression, anxiety) than did husbands; there were no differences between wives and husbands of Parkinson's care recipients. Wives of Alzheimer's patients used less problem-focused coping than did husbands. The two gender groups were similar in use of emotionfocused coping.

\section{Concerns about Alzheimer's and Dementia}

Individuals who have greater worries about getting Alzheimer's also report lower levels of psychological well-being (Cutler and Bragaru, 2015). Continuous worries about getting Alzheimer's may be termed a chronic stressor, having detrimental effects on physical and psychological health.

Martin et al. (2013) review self-management interventions for people with early stage dementia that address five areas: relationship with family, maintaining an active lifestyle, psychological well-being, techniques to cope with memory changes, and information about dementia. LoboPrabhu et al. (2005) offer guidance to caregivers providing support to recipients with dementia.

Japan, with the world's oldest population, has introduced several new 
initiatives to help families dealing with dementia. These include mandatory long-term care insurance that offers services not money, dementia daycares for families wanting a break, dementia search and rescue where trained individuals look for people with dementia who have not yet been diagnosed, and time-outs for caregivers provided by individuals who move into homes to give caregivers a time-out (Toronto Star, 2015).

The National Institutes of Health in the US identified initiatives needed to achieve their biomedical research goals related to Alzheimer's. The Alzheimer's Association in the US recently developed benchmark initiatives for the next decade for the care of individuals with Alzheimer's and the support of their caregivers (Alzheimer's Association National Plan Care and Support Milestone Workgroup, 2016). This working group reviewed the Alzheimer's care and support literature and how other countries were dealing with these issues, and noted the public policies needed for the next decade both to improve care and to support caregivers. The working group identified 75 milestone objectives for improving care (e.g., identifying and setting targets for dementia-capable workforce needs at the state and county level) and 56 milestone objectives for improving the lives of caregivers (e.g., evaluating and addressing barriers for patients and key family and friend caregivers to access and use available care and support services). They believe that, to meet the objectives of the US national plan, the US government needs to adopt their milestone objectives in the national plan.

\section{CAREGIVING - AN OVERVIEW}

About 29 percent of the US population serve as family caregivers to an ill or disabled relative, about 66 million caregivers (American Psychological Association, 2015). Most estimates suggest that 53 to 68 percent are women. Women also spend more time: 21.9 hours a week versus 17.4 hours for men. Women also perform the most difficult caregiving tasks (e.g., bathing, toileting); men do more with financial matters. About two-thirds of family caregivers work full or part time. Most caregivers come from lower income families. Some grandparents also care for their grandchildren; some children care for their sick or disabled siblings, parents and grandparents. Many caregivers are themselves older citizens. It is estimated that the numbers of caregivers will continue to rise, with about two-thirds of US citizens expected to be caregivers in the future.

There were two categories of coping efforts - increasing resources (52 percent) and reducing demands (48 percent) - and, within each of these two categories, there were three groups of initiatives: behavioral, emotional and cognitive. 
Most caregivers care for adults, with a considerably smaller number caring for both adults and children and a smaller number still caring for children only. Family caregivers can provide care for years. Family caregivers serve as an extension of the formal government-provided healthcare system. Ethnic groups differ in the amount of caregiving they perform. In the US, whites and African Americans were found to provide more care than did Hispanics and Asians. But, among older women and men, Hispanics provided more caregiving than did the three other groups.

Research findings, while not always consistent, show that caregivers indicate negative outcomes from their efforts (more stress, poorer physical and psychological health). Older caregivers and women suffer more adverse outcomes. But there are also positive aspects of caregiving, including giving back to someone who had cared for the caregiver, satisfaction in providing good care, personal growth, and more meaning in one's life.

Sadly, the needs of family caregivers are too often ignored (lack of support and respect, feelings of isolation). The health of caregivers is obviously an important element in the quality of care provided to recipients.

Informal caregivers also make a significant contribution to their countries' economies, estimated to be several billion dollars annually in the US. Families also may pay out-of-pocket costs of $\$ 5000$ to $\$ 10000$ annually as well. Further costs are incurred if caregivers decide to leave their job.

\section{EFFECTS ON CAREGIVERS - META-ANALYTIC STUDIES}

Pinquart and Sorensen (2007), using a meta-analysis of 176 studies, examined the effect of engaging in informal caregiving on caregivers' health. Older people, those less financially well off and those having low levels of social support indicated poorer health. Associations of caregiving stressors with health were stronger among older caregivers, caregivers dealing with dementia, and men. The negative effects of caregiving were strong among those caregivers who themselves were in psychological distress.

Vitaliano, Zhang and Scanlan (2003), in a meta-analysis of the relationship of 11 categories of health between caregivers and non-caregivers, reviewed findings from 23 studies. Caregivers showed a slightly greater risk of health problems than did non-caregivers.

Pinquart and Sorensen (2013) undertook a meta-analysis of 84 research studies on differences between caregivers and non-caregivers on measures of perceived stress, depression, self-efficacy, general subjective well-being 
and physical health. The largest differences were found on depression, stress, self-efficacy and general subjective well-being in favor of non-caregivers; physical health differences were smaller but still favored non-caregivers. Interestingly, even larger differences were found between dementia caregivers and non-caregivers.

\section{WORK AND WELL-BEING OUTCOMES - THE BAD NEWS}

Here are a sample of studies indicating the challenges and costs to caregivers in the sandwich generation.

Keene and Prokos (2007) considered the overlap between overwork and being in or soon to enter the sandwich generation using data from the 1992 and 2002 National Study of the Changing Workforce. The 1992 sample contained 2958 respondents; the 2002 sample contained 2626 respondents. The numbers of sandwiched workers increased from 1992 to 2002, 2.3 percent to 6.5 percent. Those expecting to be sandwiched increased from 4.5 percent to 14.8 percent, the 1992 and 2002 percentages being significantly different. Both sandwiched and non-sandwiched respondents wanted to work fewer hours. Sandwiched respondents indicated higher levels of both job demands and negative work-to-family spillover than non-sandwiched respondents. Interestingly, sandwiched and nonsandwiched workers wanted to work the same hours. Workers expecting to be sandwiched actually preferred to work longer hours, contrary to their hypothesis. Workers expecting to be sandwiched may need to work more to offset the future costs of eldercare.

Hammer and Neal (2008), based on data from 309 couples, found that between 9 and 13 percent of US households had adults 30 years of age or older who work and provide care to both children and aging parents. They project that, by 2030, about 20 percent of Americans will be over 65, increasing the number providing eldercare. These caregivers also may have children, resulting in estimates of between 30 and 40 percent of families being sandwiched. Hammer and Neal (2008) review the literature on the sandwich generation and its effects on work and the well-being outcomes of those sandwiched. While managing caregiving and work roles has been found to be associated with negative work outcomes such as high levels of stress, other studies have found positive effects of caregiving. Women have been shown to have more negative effects of caregiving than have men, with women undertaking most of the caregiving to both children and aging parents. Hammer and Neal found wives spent more time providing parent care and also had more responsibilities for children. Husbands 
worked more hours per week; wives were more likely to be in professional or managerial jobs. Women reported more personal flexibility in their work schedules to handle family responsibilities, and wives were more comfortable talking about children and parents with coworkers, and about children with supervisors. Wives indicated higher levels of depression, and more positive spillover from family to work than did husbands; husbands and wives were similar on levels of work-family conflict. Women were absent from work because of childcare or adult care responsibilities more than husbands.

Voyandoff and Donnelly (1999), in a study of mothers and fathers having children at home and aging parents, reported that the number of hours spent helping and caring for parents was associated with psychological distress for mothers but not fathers. In addition, levels of job satisfaction, marital happiness and family closeness were negatively related to psychological distress.

Duxbury et al. (2011), using data from a large sample of Canadian caregivers (over 30000), some falling into the sandwich generation and others not, considered the relationship of caregiving stress and health indicators. Three types of strain were examined: physical, emotional and financial. Health outcomes included perceived stress, depressed mood, life satisfaction and perceived physical health. They also measured where the care recipient lived relative to the care provider (same residence, nearby, far away) and family type (only eldercare, both eldercare and childcare). They reported the following:

- Respondents with care recipients in their homes reported more physical and emotional strain than when care recipients lived nearby or lived further away.

- Women caregivers reported more physical and emotional strain than did men.

- Family type results showed that caregivers having only eldercare responsibilities reported higher levels of both physical and emotional stress than did sandwich generation family types.

- Emotional strain was a significant predictor of all four health outcomes; physical strain did not predict any of the four. This however may have resulted from the significant correlation of the two strain measures.

Duxbury and Dole (2014) present findings from a large Canadian study on balancing work and caregiving. The study was originally carried out by Duxbury and Higgins (2013) in 2011 and 2012. The study included both surveys and interviews. Almost 8000 completed a caregiver part of the 
survey, and 11 people were interviewed. Sixty percent of the caregivers were in the sandwich generation, and 40 percent had only eldercare responsibilities. The caregiving sample looked after multiple family members in their 70s. Most (90 percent) viewed caregiving as a family responsibility, and most took on this responsibility ( 83 percent). Most recipients of care lived within an hour's drive of the care providers.

Sandwich caregivers had many demands on their time. These included children -1 to 10 hours a week with older children and more than 30 hours a week with younger children. Eldercare took 11 hours a week by the main caregiver and 6 hours a week by the main caregiver's partner. Paid employment occupied 45 hours a week or more for 60 percent of respondents, and 55 percent did work at home at nights and over weekends. Caregiving involved primarily the provision of emotional support.

The data showed a strong link between demands of caregiving and respondents' health. Dependent care increased levels of stress, particularly depression, overload, work-family interference, more absenteeism from work, lower work productivity, more use of company benefits, less time for sleep and less time for social activities. Caregivers were more likely to be absent from work, use company benefits more often and turn down promotions. They showed a decline in productivity, worked fewer hours and indicated higher levels of stress and burnout.

Stephens et al. (1994) studied the stress and rewards experience on well-being for 95 women in three separate roles: caregiver, mother and wife. Well-being consisted of physical health, positive affect, negative affect and role overload. Role rewards explained additional variance on all well-being measures beyond that attributed to role stress. Greater stress across all four well-being outcomes was related to poorer well-being; role rewards across the three roles were related to higher levels of well-being. Thus experiences in any one role were likely to affect experiences in one or more of the other roles as well.

Stephens et al. (2001), in a study of 278 women occupying four roles (personal care provider, mother to children at home, wife, employee), reported that women indicating parent care conflict, compared to women indicating no parent care conflict, had fewer financial resources, had older children, and cared for parents with greater impairment. In addition, conflict between the parent care role and the other roles mediated the relationship between parent care stress and psychosocial well-being.

Tuithof et al. (2015), based on nationally representative face-to-face surveys of respondents in the Netherlands $(n=5305)$ aged 20 to 68 , studied emotional disorders among informal caregivers in the general population. 
Informal caregivers were defined as providing unpaid care in the 12 months before the survey to a family member, partner or friend who needed care for physical, mental or aging difficulties. Emotional disorders included mood and anxiety disorders. In the previous year, 31 percent of respondents provided informal care, eight or more hours a week (32 percent) and of long duration (longer than one year, 49 percent). While informal caregiving was not associated with having any 12 month emotional disorders, those giving care to first-degree relatives, partners or close friends and giving emotional support increased the risk of all disorders. Informal caregivers with limited resources (being unemployed), lacking social support, and living with the care recipient were at particular risk.

Hansen and Slagsvold (2013), using two data sets (the first crosssectional data from 15000 Norwegian men and women aged 40-84, and the second a two wave panel data sample of about 3000 Norwegian women and men aged 40-84), studied the psychological effects of providing care to a partner. Caregivers and non-caregivers with disabled and non-disabled partners were compared on cognitive (e.g., life satisfaction), psychological (e.g., self-esteem, mastery) and affective well-being (e.g., happiness, depression). Caregiving was found to have both cross-sectional and longitudinal detrimental effects across all aspects of well-being. Caregiver effects were stronger among caregivers with health problems.

\section{WOMEN CAREGIVERS AT GREATER RISK}

Yee and Schulz (2000) reviewed the literature on gender differences in psychiatric morbidity in 11 articles. In almost all the studies examined, female caregivers reported more psychiatric symptoms than did male caregivers. Female caregivers also reported excess psychiatric morbidity attributable to caregiving than did females in non-caregiving community samples. Using a stress process model, the researchers concluded that, at all stages of this process (demands, appraisal, stress, negative responses), females were at greater risk of psychiatric morbidity than were males. They suggest that it is important to address women's caregiving early in the process before they suffer serious mental health symptoms. Adult daycare and respite programs and encouraging women to be more assertive in seeking help are valuable steps. Helping caregivers deal with negative emotions and feelings of burden through counseling could follow. The utilization of support groups that encourage caregivers to express their concerns and challenges and learn from other caregivers is also relevant. Men can benefit from these programs as well. 


\section{WORK AND WELL-BEING OUTCOMES OF CAREGIVERS IN THE SANDWICH GENERATION - SOME GOOD NEWS}

Zacher et al. (2012) collected data from 165 employed respondents in Germany providing in-home eldercare and from a colleague and a family member of each employee. Eldercare demands were assessed by family members using a survey. Work performance was assessed by respondents and coworkers, again using a survey. Mental health included bodily pain, vitality and physical and social functioning. Finally, satisfaction with caregiving tasks was assessed by one global item. Satisfaction with eldercare tasks moderated the relationship between eldercare demands and work performance, while mental health mediated this moderating effect. That is, care providers indicating higher levels of their own mental health benefited more from the higher levels of satisfaction with eldercare tasks. The researchers suggest that interventions that increase employee satisfaction with their eldercare tasks would protect caregiving employees from the negative effects of eldercare task demands on mental health and improve job performance.

Greenberger and Litwin (2003) surveyed 240 randomly sampled spousal and filial caregivers in Jerusalem. The survey included background variables, personal resources (mastery and self-esteem), personal social support, role-specific social support, access to formal support, burden, caregiver competence, and several outcome variables reflecting healthcare facilitation. Behaviors facilitating recipient healthcare were positively related to the presence of personal and social resources (mastery and social support) and to burden. The latter relationship was contrary to expectations, perhaps resulting from the nature of their burden measure.

\section{BENEFITS TO CAREGIVERS}

It turns out that many caregivers report benefits from taking care of others. These include developing better relationships with their parents, using particular skills, developing new skills, and the satisfaction of giving to another. There are also other benefits to caregivers, including increased marital happiness (Ward and Spitze, 1998), role satisfaction (Stephens et al., 1994), aging parents giving care and help to other family members (Ingersoll-Dayton et al., 2001), and reciprocity of care between caregivers and recipients (Ingersoll-Dayton et al., 2001). 


\section{Benefits to Caregivers of Being Employed}

Hansen and Slagsvold (2013) examined the effects of both informal caregiving and being employed on the psychological well-being of caregivers. They consider partner and parent care recipients and distinguish between in-household and out-of-household caregivers. Data were collected in Norway from 11047 respondents aged 25 to 64. Six dimensions of psychological well-being were considered. In-household caregiving was associated with lower psychological well-being among women who did not work full time. Out-of-household caregiving had no effect on women's or men's well-being irrespective of employment status. Women engaged in caregiving with limited employment may have been double disadvantaged in not being able to access all the benefits given to those working full time.

Hansen and Slagsvold (2015) examined the question of whether employment helps or harms caregivers by increasing levels of stress. They used cross-sectional data from over 11000 Norwegians aged 25-64. They found that full-time caregivers' employment had benefits to caregivers.

\section{WHY ORGANIZATIONS SHOULD CARE}

Backett-Milburn et al. (2008) studied how women working in the retail food industry combined work and looking after children or other family members. Data were obtained from 302 women working in nine organizations, with one-third also having eldercare roles caring for older people involving from one to two hours a week to four hours every day. Many of these women chose retail, as they saw it offering good opportunities to balance work and caring. These women were satisfied with their jobs and employers. Most had relatives look after their children while they worked. It became stressful when caring emergencies arose, but they were usually able to switch work shifts with coworkers. Managers however indicated that it was more difficult for them to balance work and caring and the shifts of their employees. Many worked unpaid overtime to staff their units. Caring for the elderly was more demanding than caring for children because of the recipients' poor health. These women's efforts were maintained because of their wanting to be "good mothers, daughters and family members" as well as "good employees" keeping their organizations staffed. Interestingly, and perhaps not surprisingly, most of these women did not know their rights or whether they had any.

The presence of the sandwich generation also raises challenges for organizations. As more of their middle-aged employees (likely to be longer tenured, have lots of tacit organizational knowledge, and be in more senior 
and more responsible jobs) experience overload and stress they are less likely to perform at peak levels. This becomes a concern for both individual employees and their workplaces. This shows up as increased absenteeism, more depressed mood, higher levels of stress, greater use of some company benefits, and less interest in further career advancement reflected in some cases in turning down promotions or transfers. Individuals who are sandwiched, both women and men, cope by bringing work home, sleeping less, and taking part in fewer social activities both on and off the job.

Various workplace supports are available to members of the sandwich generation, some being very helpful, others less so. Women make greater use of workplace supports than do men.

Organizations assume costs as a result of the childcare and eldercare needs of their employees. These costs show up in increased absenteeism, reduced productivity, greater intention to quit, less job satisfaction, more mental and physical health problems, and more stress and strains.

Neal and Hammer (2001) show findings from their research that indicate numerous potential benefits to employers from helping their employees manage their childcare and eldercare needs. Employees falling into the sandwich generation are somewhat unique and require special consideration. The benefits include less absenteeism, less turnover, higher levels of employee retention, being better able to attract and recruit new employees, higher levels of employee job satisfaction, higher levels of organizational engagement and commitment, improved job performance and productivity, and employees with better psychological and physical health.

\section{EFFECTS OF FAMILY AND PROGRAM SUPPORT}

Zacher and Schulz (2015), in a sample of 100 employed caregivers in Germany, examined the role of perceived support from three sources (organization, supervisor, coworkers) on the eldercare demands-strain relationship. Eldercare demands were measured by the number of hours spent per week on eldercare-related activities, while strain was measured by psychosomatic complaints. Higher levels of demands were positively related to strain, support was negatively related to strain, and high support weakened the demand-strain relationship.

Chen et al. (2010) evaluated types of support available to caregivers from a federal- and state-funded Family Caregiver Support Program (FCSP) and caregiver outcomes. Data were collected from 164 caregivers using surveys. Caregiver services typically provide information access, caregiver education and training, respite and supplemental services. Research findings on the effects of these services have produced mixed results in the past. Chen 
and her colleagues found that their caregivers making greater use of FCSP services were more satisfied with the services provided.

Malhotra et al. (2012), using data from 1190 dyads consisting of community care recipients 75 years of age or older and caregivers (family member, friend most involved in caregiving), studied predictors of caregiver depressive symptoms. Primary stressors, perceived emotional support, and caregiver health status were directly or indirectly associated with caregiver depressive symptoms, and this relationship was mediated by negative reactions to caregiving.

Riley and Bowen (2005), with an emphasis on women caregivers in the sandwich generation, suggest counseling interventions as one way to strengthen their understanding of the dynamics of caregiving, increase their resources, and lessen the burden of these responsibilities.

\section{THE IMPORTANCE OF ORGANIZATIONAL SUPPORT}

Zacher and Winter (2011), in a sample of 147 employees providing eldercare, reported that perceived organization eldercare support reduced the positive relationship between eldercare demands and stress and reduced the negative relationship between eldercare strain and work engagement. Perceived eldercare support was particularly helpful for employees' work engagement when both eldercare demands and strain levels were high.

Kim, Ingersoll-Dayton and Kwak (2011), in a study of 652 employed caregivers to older adults, found that work interference mediated the relationship between caregivers' stress and their job performance appraisals at work, whereas perceived employer support moderated the relationship between work interruptions and caregiver stress on their job performance appraisals.

Buffardi et al. (1999), based on a sample of 18120 US federal employees in dual-income households, reported that eldercare responsibilities were correlated with lower levels of satisfaction with perceived organizational support, pay, leave benefits, and work-family balance, while the negative effects of childcare were only related to leave benefits and work-family balance.

\section{THE VALUE OF ORGANIZATIONAL INITIATIVES}

Dembe et al. (2008) collected data from 115 senior level human resource and employee benefits managers at large US organizations about nine types of eldercare services. Respondents indicated that eldercare services 
worked to lessen absenteeism, reduce employee stress and increase productivity. They believed that flexible work scheduling and leave programs had the greatest benefits for employee recruitment and retention. But employee use of eldercare services was low, owing to lack of employee awareness of the services, employer concerns about program costs, and the inability of organizations to determine their actual value.

Eldercare assistance is sometimes provided at work. Dembe et al. (2008) listed nine formal eldercare services provided by some organizations in the US: counseling, resources and referral services, eldercare management services, dependent care flexibility spending accounts, dependent care reimbursement programs, long-term care insurance for elderly dependents, flexible work schedules and leave programs, emergency short-term eldercare, and on-site adult daycare.

Zuba and Schneider (2013), using a large sample of European employed women and men, studied the influence of organizational characteristics in balancing work and eldercare responsibilities. They compared the responses of carers and non-carers on role conflict and workplace absenteeism. Caregivers reported higher levels of work-family conflict. However, work schedules and time regimes affected work-family conflict in both carers and non-carers. Work overload and informal support at work had a large impact on work-family conflict. Work-family conflict influenced workplace absenteeism as a function of workplace polices.

Lauzon et al. (2010) studied how supervisors responded to work-life balance requests for work-life accommodations. Over 1000 employee requests for accommodation were examined. Schedule changes and increased flexibility were the most requested accommodations and were agreed to 58 percent of the time. The most frequent reason for not agreeing to the request was lack of authority on the part of the supervisor. Requests for more work resources and changes to work schedules were accommodated 81 percent and 44 percent of the time.

Calvano (2015) describes employee initiated eldercare support groups started in workplaces with formal organizational support, and organizations offering eldercare support services in partnership with outside agencies as part of their employee benefit packages.

Organizations must do more to support their caregiving employees. About three-quarters of caregivers work either full time or part time. The stress of caregiving costs organizations billions of dollars each year from absenteeism, employees arriving late and leaving early, some quitting their jobs entirely, others switching to part-time work from full-time, and some refusing promotions and jobs requiring travel. In addition, employees are unlikely to commit all of their energy and resources while at work because of their caregiving demands. Employers should not discriminate against 
caregiving employees, and should consider offering flextime work arrangements to employees, train supervisors in the needs of caregivers, and create on-site support groups.

Barnett et al. (2009), in a sample of 572 employed caregivers ( 75 percent women), examined the effects of usable flexibility at work on job withdrawal (e.g., taking leave of absence, working fewer hours), as influenced by caregiver concerns (e.g., adequacy of care, safety of recipient). Caregiving concerns mediated the relationship of both work flexibility and planned job changes. Employed caregivers lacking usable flexibility reported higher levels of caregiver concerns, which in turn was related to planning or considering job changes in the next year. Respondents indicated also that using flextime policies would likely have negative career consequences.

Austen and Ong (2013), in a longitudinal study of 2416 mid-life Australian women (aged 45 to 69), studied the effects of ill health and informal care roles and women's employment, and how workplace characteristics mediate these relationships. First, they reported that women in jobs with low skills and status had the greatest difficulty in accommodating to changes in their health and informal care roles. Second, paid sick leave and holiday leave increased women's job retention. Third, among women who preferred working fewer hours there was a greater intention to leave the workforce. Women working full time and holding permanent position contracts had greater access to flexibility options than did women working part time or on temporary contracts. The researchers concluded that more organizations need to develop policies that maintain the workforce participation of these women, part of an increasing aging population.

Seaward (1999) proposes services that employing organizations can offer employees to increase productivity and describes company initiatives making eldercare benefits to employees. She cites costs of eldercare to US organizations of over $\$ 11$ billion a year, increasing to over $\$ 29$ billion a year if part-time workers were increased (costs being associated with decreased productivity and increased healthcare costs). Potential initiatives include resource and referral services, flexible work schedules, family care leave of absence, dependent care assistance accounts, intergenerational daycare centers and long-term care insurance. Employed caregivers who provide eldercare need to know and understand the benefits available to them, get their supervisors on board, and keep working to retain provided benefits.

Katz et al. (2011) included quantitative data from 100 employers and also interviewed 13 employers in Israel. Organizational representatives saw caregiving as causing disruptions in the workplace through absenteeism, lateness in coming to work, and leaving work early. Most employers had no policy on workers caring for aging family members, with half the employers not supporting such policies. 
Neal et al. (1993) developed three categories of organizational-based support helpful to sandwich generation caregivers. The three categories of support were policies, benefits and services. Policies include flexible work schedules, reduced work hours, options for various types of leaves (family, sick), changes in where work can be done, and increasing management sensitivity to the work and family needs of sandwichers. Benefits include tax benefits, flexible benefit plans, health insurance coverage, and employee assistance programs offering stress management, crisis intervention, and personal and family counseling. Services include the provision of education on caregiving, the availability of resources on caregiving, the creation of direct services such as on-site childcare and eldercare centers, the availability of sick and emergency care, before-, after- and vacation-care facilities, concierge services, and linkages with external community care-related resources.

\section{WAYS USING TECHNOLOGY CAN HELP}

Blusi et al. (2013) studied the effects of the use of information and communication technologies (ICT) on the experiences of 31 family caregivers in rural regions of Sweden in their caregiving and support services. Participants were provided with a computer and high speed internet in their homes and trained in their use. Use of ICT improved the life of caregivers. Training and encouraging the use of ICT were important. Caregivers were less lonely, felt less isolated, and developed stronger relationships with relatives living in other parts of the country and elsewhere. Use of ICT also strengthened the relationship of the older caregivers and adult grandchildren.

\section{UNFORTUNATELY LITTLE ORGANIZATION SUPPORT}

Zeytinoglu et al. (2010) examined the availability of employer offered childcare and eldercare support in Canada using 2003 national survey data. Their results indicated that very few childcare initiatives and even fewer eldercare initiatives were being offered. Interestingly, women were less likely than men to be offered family support programs. Full-time employees were more likely to be offered family support programs than voluntary and involuntary part-time employees. In light of these data, the researchers argue for a significant increase in government-sponsored support for both childcare and eldercare programs. We hope that more 
Canadian organizations now offer such programs, since almost 15 years has passed since the data were collected.

\section{INTEGRATING THE PARTS AND ACTORS}

Schroeder et al. (2012) review the status of older workers having caregiving responsibilities in Canada. De Meijer et al. (2013), using data from Western countries, showed that population aging increased expenditures moderately, primarily the result of greater use of medical technology, and also the result of a greater need for acute care and more expenditure on long-term care. Canada is facing pressure to contain healthcare costs, with the result that more Canadians will provide care in their homes to the disabled and those with chronic health conditions. More employed Canadians will experience work-family conflict as a result, with implications for their own health, finances, job performance and decision to remain in the workforce. The researchers also believe that Canadian organizations have done little to assist caregiving. These economic, social and demographic factors are influencing older employed caregivers in Canada, and certainly in other countries as well. Employees, communities, employers, businesses and governments are being affected by these forces.

- Caregiving employees are pressed for time, their work performance may be affected, their health and well-being are at risk, and their finances will be challenged.

- Communities are affected in having to provide care for their citizens, help caregivers care for themselves, help caregivers gain access to external supports, resources and services, and foster social support networks.

- Employers are affected in terms of employee recruitment and retention, absenteeism, diminished work performance, and increased healthcare costs.

- Businesses are affected by lost productivity and increasing costs due to absenteeism and healthcare.

- Governments are affected by high healthcare and income security costs, but they gain considerably from the unpaid contributions of informal caregivers.

Each of these five "actors" has a role to play in addressing these emerging trends. Governments must develop home and community care policies, workplace policies, and income and pension security policies. Businesses 
need to develop human resource policies supportive of work-family balance, and work with health and social service organizations. Employers need to build support to address work-family balance concerns, create access to community supports, and increase workplace flexibility. Communities need to make available caregiver information, education, support and respite programs, integrate health, community and social services, and encourage and support community partnerships. Older caregiving employees need to find support to help them manage work and caregiving, and monitor their own health and well-being.

Organizations and governments are more aware of the negative impacts of caregiving in terms of worker productivity and public costs of long-term care for older adults. Individuals, organizations and governments play a role in reducing these effects. Public policies and organizational initiatives are just beginning to be developed.

The healthcare systems of most (or all) countries were not designed to meet the current and future needs of elderly patients (Gorin, 2002). The system needs to do a much better job addressing issues in home care and community care.

First, governments will need to be more active in making home care available to their citizens. This will require considerable organizational, management and financial support. The province of Ontario, in which I live, identified several challenges at least five years ago (long wait times, lack of standards on what services people should receive, and different levels of service at different times of the year depending on budget). Some patients had to wait one year before their initial assessments. Countries also need to focus more attention on government policy on population aging.

\section{HOME CARE AND NURSING HOME CARE - NOT AN EITHER-OR}

Individuals requiring care often live at home with a family member or paid individuals providing care. Individuals requiring care also live in nursing homes. In Ontario, tens of thousands live in nursing homes, with thousands more on waiting lists. As more people require care, there is a need to create more nursing homes in the future. Unfortunately, most societies have failed to provide the type and quality of care required by the elderly. Media stories also focus on clients being abused, poor quality food, individuals walking away from their nursing homes, and visions of tens of people crowded around the television looking spaced out. It doesn't have to be this way. 
Baines and Armstrong (2015), using a team of 26 researchers and over 50 graduate assistants in six countries, document innovative practices in long-term residential care for the elderly. They show ways in which longterm care can be organized and implemented to respond to the needs of elderly residents, families, care workers and their managers. Their report addresses four major issues:

- Approaches to care. What does compassionate care look like?

- Work organization. What organization of work and rewards meets the needs of all stakeholders?

- Accountability. What types of accountabilities result in compassionate caregiving?

- Finances and ownership. What financial and ownership models provide quality long-term care?

The researchers undertook case studies of long-term care facilities in six countries using interviews, participant observation, examination of documents, and discussions with all levels of staff, residents and family members. Case studies ranged from a single day to several days.

Among the progressive practices identified were the following: 24 hour nutrition, creating a socially connected, active and homelike environment, including housekeeping workers as part of the caregiving team, developing resident-centered care, using the dining experiences as a key part of caregiving, involving residents in food preparation, having residents live in units, high quality food, innovative physical design of space, using music as background and music therapy, staffing levels that allow time for care, a consistent philosophy of care and strong leadership, training for staff, and a resident council. The researchers then provide dozens of more specific initiatives in each of these areas.

There are some important implications that follow from these promising practices. These include adequate staffing levels and an appropriate staff mix, a stable workforce, adequate time for caregiving, enforcing high standards, training and education of staff, supportive working conditions, and the integration of nursing home care into the overall health system. The good news is that implementing these "promising practices" may not add much to the costs of caregiving for the elderly.

We also need to start caring for caregivers. Fast (2015) identifies four elements in a comprehensive caregiver strategy: acknowledge the value of family caregivers' work and their right to have a life; make adequate accessible and affordable services available to caregivers and care receivers; develop organizational workplace policies so caregivers can continue 
to work while providing caregiving; and provide financial support to those in need.

\section{OVERVIEW OF RESEARCH FINDINGS}

The numbers of employees in the sandwich generation will increase over time. Those in the sandwich generation are responsible for their children and aging parents. This results from the facts that the population is aging because of increases in life expectancy, and declining fertility has increased the aging of the population. The demands for care of an increasingly aging population will then increase. Eldercare and childcare are different in that eldercare is more demanding and increases in intensity over time. Caregivers provide financially uncompensated care and help to family members. Women do considerably more of the caregiving. Caregiving has both emotional and instrumental elements. Families also have unequal access to caregiving resources.

Being sandwiched has negative impacts on the labor market as well more absenteeism and lateness, less productivity, less career mobility. But there are some benefits of being sandwiched. There is a possibility of the marital relationship becoming stronger in sandwiched couples. Caregiving involves both direct care (feeding, bathing, making meals, ensuring medication regimens are followed) and managerial roles (dealing with physicians, dealing with insurance companies, paying bills). Caregiving relationships are complicated in terms of gender, parents versus parents-in-laws, places of residence, ethnicity and culture.

Eldercare has been found to impact the physical and psychological health of caregivers. Caregivers report higher levels of stress than do non-caregivers; caring for elders is more stressful than caring for children; psychological health is more adversely affected in caregiving than is physical health; caring for a spouse is more stressful than caring for a parent; caring for someone with Alzheimer's or dementia is particularly stressful; low income caregivers report higher levels of stress than do wealthier caregivers.

Most caregivers are also employees. Caregivers report more work-family conflict than do non-caregivers. And employers sometimes hold negative perceptions of the job performance and productivity of caregivers. In addition, caregivers take more time off work, are less willing to travel as part of their jobs, are less interested in promotions, and switch to part-time work from full-time work. As a result there is a stigmatization of sandwich women and men in many workplaces.

Women were more than twice as likely as men to be caregivers in the 
sandwich generation; they spent more time than men in childcare, and more time than men in eldercare. Women provided more emotional support than tangible support (money, undertaking tasks). Women found almost all caring variables more demanding than did men, and consequently reported greater levels of stress and depression.

\section{ADVICE TO CAREGIVING SANDWICH GENERATION WOMEN AND MEN}

There is now a wealth of information available to sandwich generation women and men who are caregivers. Some of these tips include:

- Make sure you take care of yourself as a caregiver.

- Obtain information on caregiving and on long-term disabilities.

- Search out available government programs or policies on support for eldercare.

- Talk with your parents about their situation and the available options.

- Talk with and get help from an eldercare professional.

- Take advantage of flexible work arrangements.

- Schedule some time to spend by yourself or with your spouse.

- Ask others for help.

- Learn to say "no."

- Hire a housekeeper.

- Seek out possible financial compensation or tax breaks.

- Choose a job with flexible work schedules:

- Work at home.

- Use family-friendly workplace policies if possible to reduce your work time.

- Gear down your lifestyle.

- Take one day at a time.

- Don't try to be everything to everybody.

- Set priorities and budget accordingly.

- Keep communication flowing.

- Use a large calendar to schedule family activities.

- Plan for your own future.

- Have patience.

- Don't lose yourself in the process.

- Use counseling help if needed.

- Communicate - talk with aging parents about medical decisions and long-term care. 
- Share the load among family members.

- Use outside resources - from the workplace, or government provided.

- Obtain critical information from your parents.

- Be proactive.

\section{Discussions with Aging Parents}

Here are some things to discuss with one's aging parents:

- the lifestyle they would like in retirement;

- their retirement incomes;

- their monthly expenses;

- what investments they may have;

- their estate planning;

- whatever health insurance they may have.

\section{What Employers Can Do}

Organizations can have a huge impact on the experiences of their sandwich women and men. Some initiatives include the following:

- Understand the needs of sandwich generation employees.

- Offer more flexibility at work in terms of when hours can be worked and where hours can be worked, and compressing a work week into four days instead of five.

- Offer more support for childcare and eldercare.

- Include eldercare counseling as part of an employee assistance program.

- Include content on childcare and eldercare in management training programs.

- Train supervisors to be more sensitive to the childcare and eldercare needs of employees.

- Remove the stigma of being an eldercare provider.

- Encourage overloaded and stressed employees to use the employee assistance program.

- Offer seminars on the sandwich generation phenomenon.

- Offer back-up family care - pay up to 80 hours per year of in-home care.

- Create flexible spending accounts for dependent care.

- Develop work-family programs, and family-friendly policies. 


\section{What Governments Can Do to Support Caregivers}

- Implement family-friendly polices and practices in government workplaces.

- Provide more government funding to informal caregivers.

- Pay family caregivers.

- Provide tax credits for caregiving.

\section{NOTE}

Carla D'Agostino provided administrative support, and her daughter Jessica D'Agostino assisted in the identification and collection of relevant materials. My participation was supported in part by York University.

\section{REFERENCES}

Alzheimer's Association National Plan Care and Support Milestone Workgroup (2016). Report on milestones for care and support under the U.S. National Plan to address Alzheimer's disease. Alzheimer's and Dementia, 12, 334-369.

American Psychological Association (2015). Eldercare: More than "parenting a parent." Washington, DC: American Psychological Association Help Center.

Austen, S. and Ong, R. (2013). The effects of ill health and informal care roles on the employment retention of mid-life women: Does the workplace matter? Journal of Industrial Relations, 55, 663-680.

Backett-Milburn, K., Airey, L., McKie, L. and Hogg, G. (2008). Family comes first or open all hours? How low paid women working in food retailing manage webs of obligation at home and work. Sociological Review, 56, 474-496.

Baines, D. and Armstrong, P. (2015). Promising practices in long term care. Toronto: Canadian Centre for Policy Alternatives.

Barbosa, F. and Matos, A.D. (2014). Informal support in Portugal by individuals aged 50+. European Journal of Ageing, 11, 293-300.

Barnett, R.C., Gareis, K.C., Gordon, J.R. and Brennan, R.T. (2009). Usable flexibility, employees' concerns about elders, gender, and job withdrawal. Psychologist-Manager Journal, 12, 50-71.

Blusi, M., Asplund, K. and Jong, M. (2013). Older family caregivers in rural areas: Experiences from using caregiving support services based on information and communications technology (ICT). European Journal of Ageing, 10, 191-199.

Buffardi, L.C., Smith, J.L., O’Brien, A.S. and Erdwins, C.J. (1999). The impact of dependent care responsibility and gender on work attitudes. Journal of Occupational Health Psychology, 4, 356-367.

Calvano, L. (2013). Tug of war: Caring for our elders while remaining productive at work. Academy of Management Perspectives, 27, 204-217.

Calvano, L. (2015). Balancing eldercare and work. In R.J. Burke, C.L. Cooper and A.S. Antoniou (eds), The multi-generational and aging workforce: Challenges and 
opportunities (pp. 165-182). Cheltenham, UK and Northampton, MA, USA: Edward Elgar.

Carers UK (2013). Supporting working carers: The benefits to families, business and the economy. London: Carers UK.

Caro, F.G. (2007). Family and aging policy. Binghamton, NY: Haworth Press.

Chen, Y.-M., Hedrack, S.C. and Young, H.M. (2010). A pilot evaluation of the Family Caregiver Support Program. Evaluation and Program Planning, 33, 111-119.

Chisholm, J. (1999). The sandwich generation. Journal of Social Distress and the Homeless, 8, 177-191.

Couch, K., Daly, M. and Wolf, D. (1999). Time? Money? Both? Allocation of resources to older parents. Demography, 36, 219-232.

Cravey, T. and Mitra, A. (2011). Demographics of the sandwich generation by race and ethnicity in the United States. Journal of Social Economics, 40, 306-311.

Cutler, S.J. and Bragaru, C. (2015). Long-term and short-term predictors of worries about getting Alzheimer's disease. European Journal of Ageing, 12, 75-86.

de Meijer, C., Wouterse, B., Polder, J. and Koopmanschap, M. (2013). The effect of population aging on health expenditure growth: Critical review. European Journal of Ageing, 10, 353-361.

Del Campo, R.G., Cook, A. and Arthur, M.M. (2013). Cultural differences in work-family policies and perceptions of organizational support. Employee Responsibilities and Rights, 25, 23-39.

Dembe, A.E., Dugan, K., Mutschler, P. and Piktialis, D. (2008). Employer perceptions of elder care assistance programs. Journal of Workplace Behavioral Health, 23, 359-379.

DeRigne, L. and Ferrante, S. (2012). The sandwich generation: A review of the literature. Florida Public Health Review, 9, 95-104.

Dhar, V.E. (2011). Transnational caregiving: Part 1, caring for family relations across nations. Care Management Journal, 12, 60-71.

Duxbury, L. and Dole, G. (2014). Suspended in the middle: Balancing paid employment, childcare and eldercare. In R.J. Burke, K.M. Page and C.L. Cooper (eds), Flourishing in life, work and careers (pp.141-166). Cheltenham, UK and Northampton, MA, USA: Edward Elgar.

Duxbury, L. and Higgins, C. (2013). Balancing work, childcare and eldercare: A view from the trenches. Ottawa: Sprott School of Business.

Duxbury, L., Higgins, C. and Smart, R. (2011). Elder care and the impact of caregiver strain on the health of employed caregivers. Work, 40, 29-40.

England, M. and Tripp-Reimer, T. (2003). Imminent concerns of filial caregivers reporting recent experiences of crisis. International Journal of Aging and Human Development, 56, 67-88.

Fast, J. (2015). Caregiving for older adults with disabilities. Montreal: Institute for Research on Public Policy.

Freeman, S. (2015). Adult children hinder retirement. Toronto Star, September $3, \mathrm{~B} 1$.

Gorin, S. (2002). Crisis in caregiving: A call to action. Health and Social Work, 27, 307-311.

Greenberger, H. and Litwin, H. (2003). Can burdened caregivers be effective facilitators of elder care-recipient health care? Journal of Advanced Nursing, 41, $333-341$.

Grundy, E. and Henretta, J. (2006). Between elderly parents and adult children: A 
new look at the intergenerational care provided by the "sandwich generation." Ageing and Society, 26, 707-724.

Hammer, L.B. and Neal, M. (2008). Working sandwich-generation caregivers: Prevalence, characteristics, and outcomes. Psychologist-Manager Journal, $11,93-112$.

Hansen, T. and Slagsvold, B. (2013). The psychological effects of providing personal care to a partner: A multidimensional perspective. Health Psychology Research, 1, 126-134.

Hansen, T. and Slagsvold, B. (2015). Feeling the squeeze? The effects of combining work and informal caregiving on psychological well-being. European Journal of Ageing, 12, 51-60.

Heisler, E., Evans, G. and Moen, P. (2008). Health and social outcomes from moving to a continuing care retirement community. Journal of Housing for the Elderly, 18, 5-23.

Hooker, K., Manoogian-O'Dell, M., Monahan, D., Frazier, L.D. and Shifren, K. (2000). Does type of disease matter: Gender differences among Alzheimer's and Parkinson's disease spouse caregivers. Gerontologist, 40, 568-573.

Ingersoll-Dayton, B., Starrels, M.E. and Dowler, D. (1996). Caregiving for parents and parents-in-law: Is gender important? Gerontologist, 36, 483-491.

Ingersoll-Dayton, B., Neal, M. and Hammer, L.B. (2001). Aging parents helping adult children: The experience of the sandwiched generation. Family Relations, $50,262-271$.

Jakobsson, N., Kotsadam, A. and Szebehely, M. (2013). Informal eldercare and care for disabled children in the Nordic countries: Prevalence and relation to employment. Nordic Journal of Social Research, 4, 1-30.

Jones, P.S., Zhang, X.E., Jaceldo-Siegl, K. and Meleis, A.I. (2002). Caregiving between two cultures: An integrative experience. Journal of Transcultural Nursing, 13, 202-209.

Juin, S. (2015). Care arrangements and caregivers' health: Should we care about how they care? Paris: University of Paris.

Katz, R. (2009). Intergenerational family relations and subjective well-being in old age: A cross-cultural study. European Journal of Ageing, 6, 79-90.

Katz, R., Lowenstein, A., Prilutzky, D. and Halperin, D. (2011). Employers' knowledge and attitudes regarding organizational policy toward workers caring for aging family members. Journal of Aging and Social Policy, 23, 159-181.

Keene, J. and Prokos, A. (2007). The sandwiched generation: Multiple caregiving responsibilities and the mismatch between actual and preferred work hours. Sociological Spectrum, 27, 365-387.

Kim, J., Ingersoll-Dayton, B. and Kwak, M. (2011). Balancing eldercare and employment: The role of work interruptions and supportive employers. Journal of Applied Gerontology, 32, 347-369.

Koerin, B.B., Harrigan, M.P. and Secret, M. (2008). Eldercare and employed caregivers: A public/private responsibility? Journal of Gerontological Social Work, 51, 143-161.

Kotsadam, A. (2011). Does informal eldercare impede women's employment? The case of European welfare states. Feminist Economics, 17, 121-144.

Lashewicz, B. and Keating, N. (2009). Tensions among siblings in parent care. European Journal of Ageing, 6, 127-135.

Lauzon, H.M., Morganson, V.J., Major, D.A. and Green, A.P. (2010). Seeking 
work-life balance: Employees' requests, supervisors' responses, and organizational barriers. Psychologist-Manager Journal, 13, 184-205.

Lechner, V.A. and Gupta, C. (1996). Employed caregivers: A four-year follow-up. Journal of Applied Gerontology, 15, 102-115.

Lechner, V. and Neal, M. (1999). Work and caring for the elderly: International perspectives. Philadelphia, PA: Taylor \& Francis.

LoboPrabhu, S.M., Molinari, V.A. and Lomax, J.W. (2005). Supporting the caregiver in dementia: A guide for health care professionals. Baltimore, MD: Johns Hopkins University Press.

Malhotra, C., Malhotra, R., Ostbye, T., Matchar, D. and Chan, A. (2012). Depressive symptoms among informal caregivers of older adults: Insights from the Singapore Survey of Informal Caregiving. International Journal of Psychology and Geriatrics, 8, 1335-1346.

Martin, F., Turner, A., Wallace, L.M. and Bradbury, N. (2013). Conceptualization of self-management interventions for people with early stage dementia. European Journal of Ageing, 10, 75-87.

Miller, D. (1981). The "sandwich" generation: Adult children of the aging. Social Work, 26, 419-423.

Mudrak, J., Stochl, J., Slepicka, P. and Elavsky, S. (2015). Physical activity, selfefficacy, and quality of life in older Czech adults. European Journal of Ageing, $12,46-55$.

National Alliance for Caregiving and the American Association of Retired Persons (2004). Caregiving in the U.S. Bethesda, MD: National Alliance for Caregiving.

Neal, M.B. and Hammer, L.B. (2001). Work-family sourcebook for employees: Supporting employees with child and eldercare needs. Portland, OR: Portland State University.

Neal, M.B. and Hammer, L.B. (2007). Working couples caring for children and aging parents: Effects on work and well-being. Mahwah, NJ: Lawrence Erlbaum Associates.

Neal, M.B., Chapman, N.J., Ingersoll-Dayton, B. and Emlen, A.C. (1993). Balancing work and caregiving for children, adults and elders. Newbury Park, CA: Sage.

Neal, M.B., Ingersoll-Dayton, B. and Starrels, M.E. (1997). Gender and relationship differences in caregiving patterns and consequences among employed caregivers. Gerontologist, 37, 804-816.

Neal, M.B., Hammer, L.B., Pines, A.M., Bodner, E. and Cannon, M.L. (2013). Working caregivers in the "sandwiched generation." In J. Field, R.J. Burke and C.L. Cooper (eds), Aging, work and society (pp. 329-346). London: Sage.

Nichols, L. and Junk, V. (1997). The sandwich generation: Dependency, proximity, and task assistance needs of parents. Journal of Family and Economic Issues, 18, 299-326.

OECD (Organisation for Economic Co-operation and Development). (2011). Help wanted? Providing and paying for long term care. Paris: OECD.

Perrig-Chiello, P., Jaeggi, S.M., Buschkuehl, M., Stahelin, H.B. and Perrig, W.J. (2009). Personality in middle age as predictors for well-being and health in old age. European Journal of Ageing, 6, 27-37.

Pew Research Center (2013). The sandwich generation: Rising financial burdens for middle-aged Americans. Washington, DC: Pew Research Center.

Pines, A.M., Neal, M.B., Hammer, L.B. and Icekson, T. (2011). Job burnout and 
couple burnout in dual-earner couples in the sandwiched generation. Social Psychology Quarterly, 74, 361-386.

Pinquart, M. and Sorensen, S. (2007). Correlates of physical health of informal caregivers: A meta-analysis. Journal of Gerontology, 62, 126-137.

Pinquart, M. and Sorensen, S. (2013). Differences between caregivers and non-caregivers in psychological health and physical health: A meta-analysis. Psychological Aging, 18, 250-267.

Pyke, K. and Bengtson, V. (1996). Caring more or less: Individualistic and collectivist systems of family eldercare. Journal of Marriage and the Family, 58, 379-392.

Remennick, L. (2001). "All my life is one big nursing home": Russian immigrant women in Israel speak about double caregiver stress. Women's Studies International Forum, 24, 685-700.

Riley, L.D. and Bowen, C. (2005). The sandwich generation: Challenges and coping strategies of multigenerational families. Family Journal: Counseling and Therapy for Couples and Families, 13, 52-58.

Robison, J., Fortinsky, R., Kleppinger, A., Shugrue, N. and Porter, M. (2009). A broader view of family caregiving: Effects of caregiving and caregiver conditions on depressive symptoms, health, work, and social isolation. Journal of Gerontology: Social Sciences, 64, 788-798.

Schroeder, B., MacDonald, J. and Shamian, J. (2012). Older workers with caregiving responsibilities: A Canadian perspective on corporate caring. Ageing International, 37, 39-56.

Seaward, M. (1999). The sandwich generation copes with elder care. Benefits Quarterly, 15, 41-48.

Seltzer, M.M. and Li, L.W. (2000). The dynamics of caregiving: Transitions during a three-year prospective study. Gerontologist, 40, 165-178.

Statistics Canada (2010). Population projections for Canada: Provinces and territories 2009 to 2036. Ottawa: Statistics Canada.

Stephens, M.A., Franks, M. and Townsend, A. (1994). Stress and rewards in women's multiple roles: The case of women in the middle. Psychology and Aging, $9,45-52$.

Stephens, M.A., Townsend, A.L., Martire, L.M. and Druley, J.A. (2001). Balancing parent care with other roles: Inter-role conflict of adult daughter caregivers. Journal of Gerontology, 56, 24-34.

Szinovacz, M.F. (2003). Caring for a demented relative at home: Effective parent-adolescent relationships and family dynamics. Journal of Aging Studies, $17,445-473$.

Toronto Star (2015). An aging country becomes a dementia pioneer. November 21, WD4-WD5.

Tuithof, M., ten Have, M., van Dorsselaer, S. and de Graaf, R. (2015). Emotional disorders among informal caregivers in the general population: Target groups for prevention. Psychiatry, 15, 15-23.

Vitaliano, P.P., Zhang, J. and Scanlan, J.M. (2003). Is caregiving hazardous for one's physical health? A meta-analysis. Psychological Bulletin, 129, 946-972.

Voyandoff, P. and Donnelly, B. (1999). Multiple roles and psychological distress: The intersection of the paid worker, spouse, and parent roles with the role of the adult child. Journal of Marriage and Family, 61, 725-732.

Ward, R. and Spitze, G. (1998). Sandwiched marriages: The implications of child and parent relations for marital quality in midlife. Social Forces, 77, 647-666. 
Yee, J.L. and Schulz, R. (2000). Gender differences in psychiatric morbidity among family caregivers: A review and analysis. Gerontologist, 40, 147-164.

Zacher, H. and Schulz, H. (2015). Employees' eldercare demands, strain, and perceived support. Journal of Managerial Psychology, 30 (2), 183-198.

Zacher, H. and Winter, G. (2011). Eldercare demands, strain, and work engagement: The moderating role of organizational support. Journal of Vocational Behavior, 79, 667-680.

Zacher, H., Jimmieson, N.L. and Winter, G. (2012). Eldercare demands, mental health, and work performance: The moderating role of satisfaction with eldercare tasks. Journal of Occupational Health Psychology, 17 (1), 52-64.

Zeytinoglu, I.U., Cooke, G.B. and Mann, S.L. (2010). Employer offered family support programs, gender and voluntary and involuntary part-time work. Industrial Relations, 45, 177-195.

Zhang, Y. and Goza, F.W. (2006). Who will care for the elderly in China? A review of the problems caused by China's one-child policy and their potential solutions. Journal of Aging Studies, 20, 151-164.

Zuba, M. and Schneider, U. (2013). What helps working informal caregivers? The role of workplace characteristics in balancing work and adult-care responsibilities. Journal of Family and Economic Issues, 34, 460-469. 